\title{
FURTHER RESULTS ON GENERALISED ITERATION OF ENTIRE FUNCTIONS WITH FINITE ITERATED ORDER
}

\author{
DIBYENDU BANERJEE AND BISWAJIT MANDAL
}

Abstract. We consider generalised iteration of two entire functions and study further growth properties of generalised iterated entire functions of finite iterated order.

Mathematics subject classification (2010): 30D35.

Keywords and phrases: Transcendental entire functions, generalised iteration, finite iterated order, finiteness degree, growth.

\section{REFERENCES}

[1] D. BANERJEE AND B. MANDAL, Generalised iteration of entire functions with finite iterated order, Journal of Classical Analysis, 7, 1 (2015), 47-62.

[2] D. Banerjee And N. Mondal, Maximum modulus and maximum term of generalized iterated entire functions, Bulletin of the Allahabad Mathematical Society, 27, 1 (2012), 117-131.

[3] L. G. BernaL, On growth $k$-order of solutions of a complex homogeneous linear differential equations, Proc. Amer. Math. Soc., 101, 2 (1987), 317-322.

[4] J. Clunie, The Composition of Entire and Meromorphic Functions, Mathematical Essays Dedicated to A. J. Macintyre, Ohio University Press, 1970, 75-92.

[5] W. K. Hayman, Meromorphic Functions, Clarendon Press, Oxford, 1964.

[6] L. Kinnunen, Linear differential equations with solutions of finite iterated order, Southeast Asian Bull. Math., 22, 4 (1998), 385-405.

[7] I. LAhiRI And D. K. Sharma, Growth of composite entire and meromorphic functions, Indian J. Pure Appl. Math., 26, 5 (1995), 451-458.

[8] I. LAHIRI AND D. K. SHARMA, On the growth of composite entire and meromorphic functions, Indian J. Pure Appl. Math., 35, 4 (2004), 525-543.

[9] K. NiIno And N. Smita, Growth of a composite function of entire functions, Kodai Math. J., 3, (1980), 374-379.

[10] K. NiINO AND C. C. YANG, Some growth relationships on factors of two composite entire functions, in : Factorization Theory of Meromorphic Functions and Related Topics, Marcel Dekker Inc., New York/Basel, 1982, 95-99.

[11] A. P. SingH, Growth of composite entire functions, Kodai Math. J., 8, (1985), 99-102.

[12] D. SATO, On the rate of growth of entire functions of fast growth, Bull. Amer. Math. Soc., 69, (1963), $411-414$.

[13] J. Tu, Z. X. Chen And X. M. Zheng, Composition of entire functions with finite iterated order, J. Math. Anal. Appl., 353, (2009), 295-304.

[14] Z. Z. ZHou, Growth of composite entire functions, Kodai Math. J., 9, (1986), 419-420. 